\title{
A numerical model to simulate snow-cover stratigraphy for operational avalanche forecasting
}

\author{
E. BRun, P. David, M. Sudul and G. Brunot \\ METEO-FRANCE CNRM, Centre d'Études de la Neige, 38406 Saint-Martin-d'Hères Cedex, France
}

\begin{abstract}
Laws of snow metamorphism have been introduced in a numerical model which simulates the evolution of temperature, density and liquid-water profiles of snow cover as a function of weather conditions.

To establish these laws, the authors have summarized previous studies on temperature gradient and on wet-snow metamorphism and they have also conducted metamorphism experiments on dry or wet fresh-snow samples. An original formalism was developed to allow a description of snow with parameters evolving continuously throughout time.

The introduction of laws of metamorphism has improved significantly the derivation of the settlement of internal layers and of snow-covered albedo, which depend on the simulated stratigraphy, i.e. the type and size of snow grains of different layers of the snow cover.

The model was tested during a whole winter season without any re-initialization. Comparison between the simulated characteristics of the snow cover and the observations made in the field are described in detail. The model proved itself to be very efficient in simulating accurately the evolution of the snow-cover stratigraphy throughout the whole winter season.
\end{abstract}

\section{INTRODUCTION}

Snow-cover evolution, at a given location, is governed by the prevailing meteorological conditions. An energy and mass model of snow cover, named Crocus, was developed for operational avalanche forecasting. This model proved itself to be efficient in simulating snow temperature, liquid-water content and density profiles (Brun and others, 1989). However, this model was limited, in fact, in that it did not allow for the evolution of snow-cover stratigraphy, i.e. grain-size and types of its different layers despite the fact that this stratigraphy is the basis of methods used to determine snow stability.

Snow metamorphism, both dry and wet, depends on temperature, density and liquid-water profiles which prevail in the considered layer (Colbeck, 1973, 1980, 1983). Since Crocus proved itself efficient in simulating these profiles, it is surely able to simulate the morphological evolution of each layer of a snow cover, conditional that we are able to introduce into the model a formalism and a quantification of the metamorphism laws.

The French operational avalanche-forecasting services get data on the internal characteristics of the snow cover at different locations once a week. They also get the snowcover stratigraphy but, between two pit measurements, they receive no other observations on the internal snow evolution. Some effects such as snow-crystal growth with varying surface temperature and radiation penetration (Colbeck, 1989b) are observed in Nature with much difficulty but can be easily forecast during sunny and cold days using a numerical model of snow cover and, in such a case, it is the only way to determine whether faceted crystals are growing just below the snow-cover surface. Gubler and Bader (1989) have shown how the snowtemperature-profile evolution knowledge was important during and after a snowfall in order to explain slabavalanche release.

All of these reasons show the interest in introducing snow-stratigraphy evolution in a mass and energy model of the snow cover. The purpose of this paper is to describe how the snow-metamorphism laws were introduced into the Crocus model. The new model was then tested by a field experiment throughout a whole winter at the measurement site at Col de Porte (French Alps) by comparing the simulated snow cover, characterized by its stratigraphy and profiles, to observations made automatically in situ and then continuously or by snow pits dug once a week.

\section{QUANTIFICATION OF SNOW-METAMORPHISM LAWS}

Since the beginning of snow research, metamorphism has been one of the topics on which researchers have focussed most. This derives from the fact that snow metamorphism drives snow-cover evolution and thus affects all of its properties, especially its mechanical properties and its albedo. Basic snow-metamorphism laws were soon discovered and the influence of temperature gradient 
and moisture were pointed out (the general work of De Quervain). Dry- and wet-snow metamorphism have been described from a qualitative point of view.

Colbeck $(1973,1980,1983)$ has developed the theory of the metamorphism of wet and dry snow, describing the particular effect of liquid-water content, capillary pressure, radius of curvature and temperature gradient. Giddings and LaChapelle (1962) and Colbeck (1983) deduced siom theoretical considerations growth rates of snow grains exposed to high temperature gradients. Their results agreed with those obtained by experiments on snow samples (Akitaya, 1974; Marbouty, 1980; Pahaut and Marbouty, 1981). More recently, Christon and others (1987) developed a numerical two-dimensional simulation of temperature gradient to describe geometrical effects on metamorphism.

All information obtained by theoretical methods is very useful to the understanding of snow metamorphism. Since most methods use spherical or very simple geometrical shapes to describe snow, their results cannot be used directly for an integration in a complete metamorphism model because it cannot be applied to each snow type and even more so at various stages of metamorphism. For example, Colbeck (1983) computed growth rate using geometrical or shape factors but these factors cannot be determined for each snow type, especially when snow is in intermediate states.

Difficulty comes from the fact that even homogeneous snow layers of a given type are composed of individual crystals of various shapes and sizes having always considerable variability: that is the intrinsic mechanism of metamorphism. Up to now, no mathematical description can describe accurately the natural individual arrangements of crystals. To integrate metamorphism in a numerical snow-cover model, the problem to be solved is the following: "A given snow layer being exposed to given conditions, what happens to this layer after a given time?" To solve it, we conducted metamorphsim experiments in a cold laboratory on various natural snow samples.

\section{Previous experimental investigation on snow meta- morphism}

Two complete experimental investigations on temperature gradients (Marbouty, 1980) and on wet-snow metamorphsim (Brun, 1989) have been described in the literature. They quantify the particular effects of the different parameters affecting grain-growth rate under a high temperature gradient and under controlled liquidwater content.

High temperature gradients on rounded and faceted crystals:

After having conducted high-temperature-gradient experiments on various snow types and under many experimental conditions, Marbouty summarized his results with a depth-hoar grain-growth-rate law:

$$
\bar{a}(t)=\bar{a}(0)+g\left(\frac{\partial T}{\partial z}\right) h(\rho) \phi(t)
$$

where $\bar{a}$ is grain mean apparent diameter, $t$ is time, $T$ is temperature, $z$ is the vertical coordinate and $\rho$ is snow density. The functions $f, g, h$ and $\phi$ were determined experimentally (Marbouty, 1980) and Equation (1) can be used only for snow samples already classified as rounded crystals, faceted crystals or depth hoar (classes 3,4 and 5 according to the international snow classification (Colbeck and others, 1990).

Wet-snow metamorphism of rounded crystals and wet grains:

Using an original device suitable to wet-snow samples homogeneously at controlled liquid-water contents, Brun (1989) established the grain-growth rate of snow as a function of liquid-water content:

$$
\frac{\mathrm{d} v}{\mathrm{~d} t}=v_{0}^{\prime}+v_{1}^{\prime} \theta^{3}
$$

where $v$ is the equivalent volume of snow crystals and $\theta$ is mass liquid-water content. Equation (2) is valuable for rounded crystals (class 3 ) and wet grains (class 6).

To extend the laws of dry and wet metamorphism to all other snow types, especially for fresh snow, we have conducted snow-metamorphism experiments in a cold laboratory using the devices used to establish Equations (1) and (2).

\section{Quantification of fresh-snow metamorphism}

\section{(1) Dry fresh-snow metamorphism}

Colbeck (1983) described the rules of temperature and temperature gradient on the type and rate of metamorphism. The theoretical considerations he used allowed the introduction of a "snow-enhancement factor $g$ " which must be determined either experimentally or from stereographic views. In fresh snow, the diversity of crystal shapes does not allow the easy determination of " $g$ ". We have preferred to conduct direct metamorphism experiments by submitting natural fresh snow samples to various temperature and temperature-gradient conditions. We built a device enabling us to work simultaneously under eight different conditions on snow samples from the same snowfall. Constant conditions were applied for up to 2 or 3 weeks. Every $2 \mathrm{~d}$, a sub-sample was taken at different depths from each snow sample and then characterized under a microscope. A picture-analysis system enabled us to compute the convex radius of curvature along the crystal perimeter as seen through the microscope. For each sample, the mean convex radius of curvature was determined from about 100 crystals. The relative effects of each parameter on the rate of metamorphism were deduced from their relative effects on the growth rate of the mean radius of curvature. This radius varies from $0.08 \mathrm{~mm}$ to $0.18 \mathrm{~mm}$ for fresh snow samples and it always grows during metamorphism, more quickly when conditions inclined towards faceted crystals than towards rounded crystals.

Forty-four experiments were done using six different fresh snow samples (classes 1 and 2). The results can be summarized as follows:

Metamorphism rate and type of dry fresh snow does not depend on which type of crystals snow is composed of, excepted graupels. 
The type of metamorphism involved depends only on the prevailing temperature gradient. The rate of metamorphism depends on temperature and temperature gradient when temperature gradient is less than $5^{\circ} \mathrm{C} \mathrm{m}^{-1}$, fresh snow evolving towards rounded crystals (class 3).

When the temperature gradient is higher than $5^{\circ} \mathrm{C} \mathrm{m}^{-1}$, fresh snow evolves towards faceted crystals (class 4).

Until the whole sample is composed of rounded or faceted crystals, fresh snow evolves alternatively towards one or the other shape when the gradient alternates through the threshold of $5^{\circ} \mathrm{C} \mathrm{m}^{-1}$.

When the state of "faceted crystals" is fully reached, snow evolves towards depth hoar if the gradient is higher than $15^{\circ} \mathrm{C} \mathrm{m}^{-1}$, which agrees with the results of Akitaya (1974), Marbouty (1980) and Colbeck (1983).

To describe snow evolution using metamorphism laws, it has been necessary to introduce a new formalism to describe snow as a function of continuous parameters. These parameters are dendricity, sphericity and grain-size. Dendricity varies from 1 to 0 and describes the part of the original crystal shapes which are still remaining in a snow layer. Sphericity varies between 0 and 1 and describes the ratio of rounded versus angular shapes. Figure 1 describes the relation to the international snow classification. The arrows describe the possible directions of dendricity, sphericity and size evolution.

The quantitative results of 44 experiments can be described by the following fresh-snow metamorphism model, using the original formalism described above:

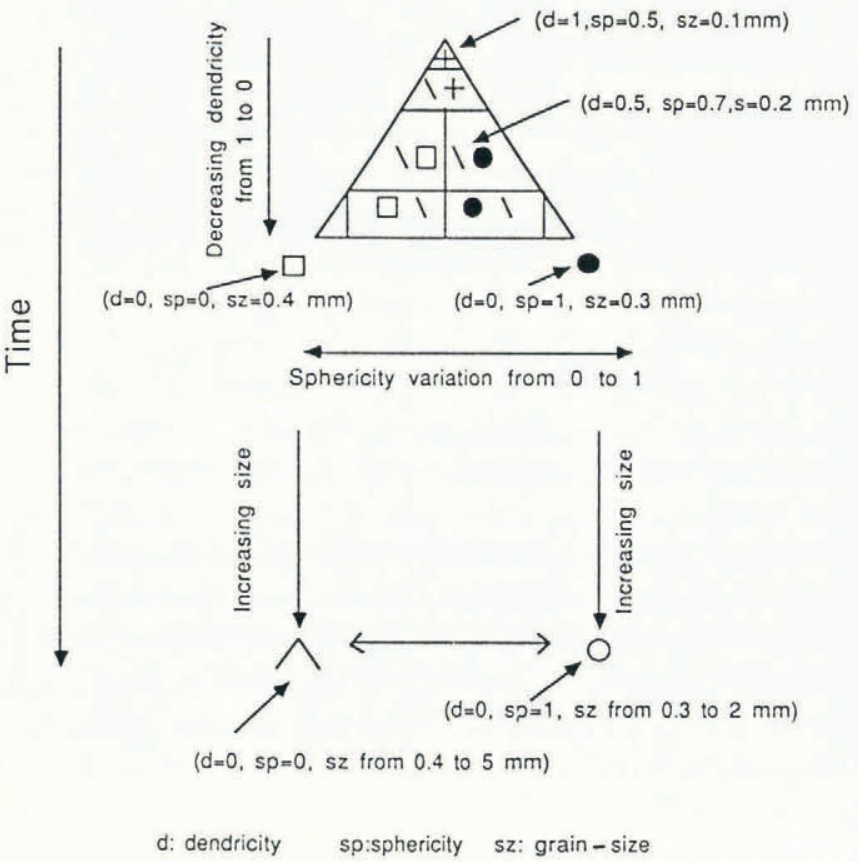

Fig. 1. Correlation between the formalism used to describe snow types with continuous parameters and the international classification. when $|\nabla T|<5^{\circ} \mathrm{Cm}^{-1}$ :

$$
\begin{aligned}
& \frac{\delta \text { dendricity }}{\delta t}=-2 \times 10^{8} \exp \left(\frac{-6 \times 10^{3}}{T}\right), \\
& \frac{\delta \text { sphericity }}{\delta t}=1 \times 10^{9} \exp \left(\frac{-6 \times 10^{3}}{T}\right)
\end{aligned}
$$

when $|\nabla T| \geq 5^{\circ} \mathrm{C} \mathrm{m}^{-1}$ :

$$
\begin{aligned}
& \frac{\delta \text { dendricity }}{\delta t}=-2 \times 10^{8} \exp \left(\frac{-6 \times 10^{3}}{T}\right)(\nabla T)^{0.4}, \\
& \frac{\delta \text { sphericity }}{\delta t}=-2 \times 10^{8} \exp \left(\frac{-6 \times 10^{3}}{T}\right)(\nabla T)^{0.4}
\end{aligned}
$$

where $t$ is time expressed in days.

When dendricity reaches 0 , partly branched crystals have almost disappeared. Snow is in the state of rounded crystals, faceted crystals or in an intermediate state, depending on the thermal history the layer has survived. It is then characterized by its sphericity ( 0 to 1$)$ and its grain-size which is in this state of about $0.3-0.4 \mathrm{~mm}$. It then evolves as a function of temperature gradient or liquid-water content, as described in the previous section. When wet-snow grains (class 6) are submitted to a temperature gradient higher than $5^{\circ} \mathrm{Cm}^{-1}$, their sphericity decreases according to Equations (4). When sphericity reaches 0 , their size increases according to the functions determined by Marbouty.

\section{Wet fresh-snow metamorphism}

Fresh snow samples have been used at the melting point and then at controlled liquid-water contents. Snow heating used dielectric absorption (Brun, 1989), which enabled us to use the whole sample at a given homogeneous liquid-water content. Every $2 \mathrm{~h}$ at the beginning of the experiment, then twice a day and then every $2 \mathrm{~d}$, sub-samples were taken out to characterize grain types under a microscope and to calculate crystal radii of curvature using picture-processing methods. Figure 2 shows the results obtained during a metamorphism experiment conducted on fresh snow at a liquid-water
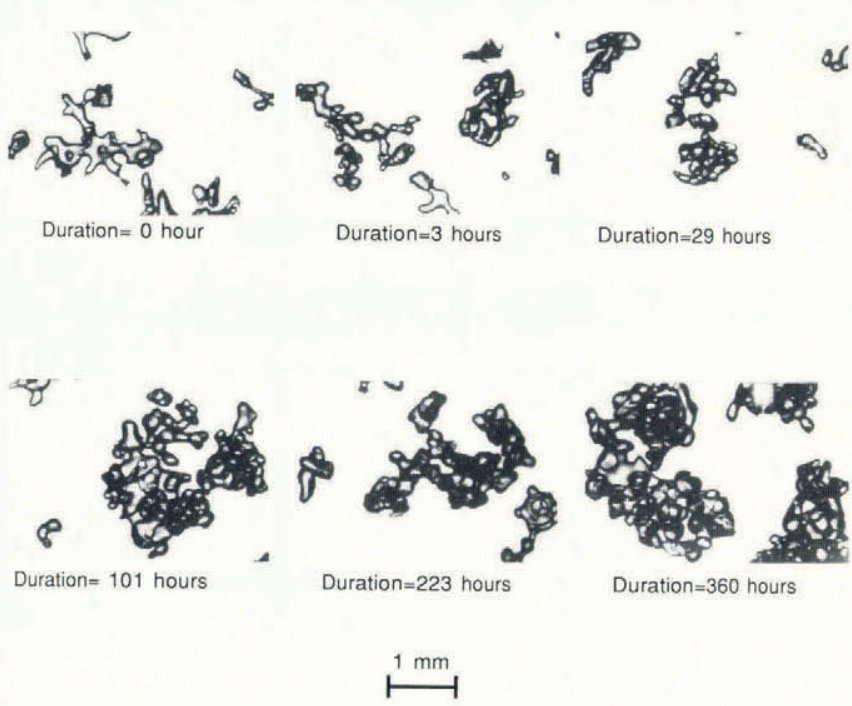

Fig. 2. Evolution of snow crystals submitted to a liquid-water content equal to $2 \%$ per mass. The duration since the end of the wetting is expressed in hours. 
content of $2 \%$ per mass. Seven experiments on fresh snow were conducted and the results can be satisfactorily described by the following equations which use the same formalism as in the previous section:

$$
\begin{aligned}
& \frac{\delta \text { dendricity }}{\delta t}=\frac{-1}{16} \theta^{3}, \\
& \frac{\delta \text { sphericity }}{\delta t}=\frac{1}{16} \theta^{3}
\end{aligned}
$$

where $\theta$ is expressed in per cent per mass and $t$ in days. When the dendricity reaches 0 , the snow reaches a state of rounded crystals whose diameter is then equal to around $0.3 \mathrm{~mm}$ and whose sphericity is equal to 1 . If wet conditions continue, snow grains grow and reach wetgrain snow (class 6), and then the growth rate is described by Equation (2).

To achieve all possible cases of metamorphism, we have submittted faceted crystals and depth hoar to wet conditions. They were reduced to wet grains and the velocity of increase in their sphericity can be described satisfactorily by Equation (5). Then, their size increases according to Equation (2). Despite their rapid rounding, the crystals retained some features of their previous faceted shapes over a few hours.

To conclude on snow metamorphism, the formalism we introduced proved itself efficient in allowing a description of all possible types of metamorphism using simple equations which were determined experimentally on all natural snow types.

\section{INTRODUCTION OF METAMORPHISM LAWS IN AN ENERGY AND MASS MODEL OF SNOW COVER}

Metamorphism laws have been introduced into the unidimensional energy and mass model Crocus whose complete description is available in Brun and others (1989). This model takes into account the different phenomena affecting the snowpack:

Energy exchanges at the snow-atmosphere interface and at the snow-soil interface using an implicit centered scheme.

Absorption of solar radiation with depth.

Phase changes between solid and liquid water.

Water transmission through the snowpack.

Mass exchanges due to precipitation and water runoff.

\section{Settlement.}

These phenomena have been derived using a time increment equal to $15 \mathrm{~min}$, except settlement which is derived once an hour. The laws of metamorphism are used just before the computation of settlement. The evolution of snow type and grain-size of each layer of the snow cover is derived once an hour from temperature, density and liquid-water-content profiles simulated during the previous hour.

When snow is falling, fresh snow layers are added to the snow cover with a dendricity equal to 1 and a sphericity equal to 0.5 . This may be different from natural conditions when wet snow is falling, but in this case, meteorological conditions will drive the model to induce a rapid wet metamorphism of the surface-snow layers, similarly as though fresh snow was added under an already evolved state. It must be noted that the model accepts mixed liquid and solid precipitation as input data.

Introducing metamorphism laws in the model Crocus has significantly improved some of the parameterizations used to simulate physical processes affecting snow cover:

Snow albedo now depends continuously on the size, type and age of the of the surface snow layer. In the previous version of the model, snow grain-size was deduced from density, though albedo does not depend directly upon it. We have introduced a decrease in albedo with snow-surface age in the spectrum range $(0.3 ; 0.8 \mu \mathrm{m})$ to take account of dry deposition which essentially affects snow albedo in the visible wave lengths (Warren, 1982). Albedo and absorption are now described by the following equations, deduced from the theoretical studies of Warren (1982) and Sergent and others (1987):

On $(0.3-0.8 \mu \mathrm{m})$ :

$$
\begin{aligned}
& \alpha=1-1.58(d)^{\frac{1}{2}}-0.2 \frac{\text { age }}{60}, \\
& \beta=0.0192 \rho \frac{1}{(d)^{\frac{1}{2}}} .
\end{aligned}
$$

On $(0.8-1.5 \mu \mathrm{m})$ :

$$
\begin{aligned}
& \alpha=1-15.4(d)^{\frac{1}{2}}, \\
& \beta=0.1098 \rho \frac{1}{(d)^{\frac{1}{2}}} .
\end{aligned}
$$

On $(1.5-2.8 \mu \mathrm{m})$ :

$$
\begin{aligned}
& \alpha=346.3 d-32.31(d)^{\frac{1}{2}}, \\
& \beta=+\infty
\end{aligned}
$$

where $\alpha$ is albedo, $\beta$ is absorption expressed in $\mathrm{cm}^{-1}, d$ is "optical" grain-size expressed in $\mathrm{m}, \rho$ is density and age is snow-surface age expressed in days and limited to 60 . The "optical" grain-size of a given snow type is the size of the spherical grains of a theoretical snow sample whose computed albedo should be equal to the albedo of the considered snow. The coefficient 0.2 involved in albedo decrease with age was fitted at Col de Porte where the nearby forest carries considerable vegetal dust in the snow cover. Under other conditions at higher altitudes or further from vegetation, this coefficient should be smaller.

Mechanical settlement depends continuously upon snow-grain type and size through its Newtonian viscosity. Transfer functions from grain type to viscosity were determined experimentally by J.P. Navarre (unpublished). 


\section{TEST OF THE MODEL}

The model has no spatial scale. Its results depend only on its input meteorological data, in such a way that it must be tested in locations where meteorological and snow data are very closely associated. The new version of the model Crocus was tested on the instrumented site at Col de Porte located $1320 \mathrm{~m}$ a.s.l. in the Massif de la Chartreuse in the French Alps. The test of the model has been made by comparing field measurements on snow cover with simulated profiles throughout a whole winter season.

\section{Field measurements}

During the winter 1988-89, input meteorological data necessary to allow the model to run were measured hourly: air temperature and humidity, wind velocity, incoming short-wave and long-wave radiation, liquid and solid precipitation. Precipitation was measured using three rain gauges, one heated, one using dissolution in alcohol and the last one unheated. Combined with snow-depth measurements, it gave good accuracy and easy distinction between snow and rain. An original device was developed to clean automatically the radiometers from fresh snow and riming once each hour.

During the same period, measurements were made on the snow cover. Snow depth, snow-surface temperature, bottom-water run-off, internal temperature profiles and snow-layer settlement were measured hourly automatically. Snow settlement was measured by following the movement of plates at different snow-layer interfaces (Brun and others, 1989). Temperature, liquid-water content and density profiles were deduced from a pit once a week. Liquid-water content was measured with a dielectric sensor of cylindrical shape $5 \mathrm{~cm}$ wide. In each layer, snow sub-samples were taken out and immersed in iso-octane at an initial temperature of $-15^{\circ} \mathrm{C}$. This action immediately inhibits metamorphism and snow grains do not evolve more significantly over many months. Snow grains were then characterized with a microscope in a cold laboratory and a picture-analysis system was used to compute different geometrical parameters and especially the mean convex radius of curvature of the crystals comprising the snow layers.

\section{Meteorological conditions encountered during the winter season 1988-89}

As in most parts of the Alps, the winter season 1988-89 has been characterized by snow precipitation from the end of November to the middle of December, followed by 2 months of warm and dry conditions. The snowpack was mostly built during the storm period from the end of February to the beginning of March. From the end of March to the middle of April, the weather was mostly warm and fair. The second half of April was characterized by heavy snowfalls followed by a rapid snowmelting at the beginning of May at middle altitudes. These conditions were perfect to test the model because all snow types appeared, even depth hoar which is not frequent at this altitude. Figure 3 describes the meteorological conditions encountered during the season.

\section{Simulation results}

The initial profiles of the snowpack were determined from a pit of 17 December. The model was run until 8 May without any re-initialization.

Figure 4 compares the simulated snow depth to that measured automatically with an ultrasonic sensor and that measured once a week from a pit. The shapes of the two continuous curves are very similar, showing that snow settlement, accumulation and melting rate are satisfactorily simulated. However, we should remark on a gap

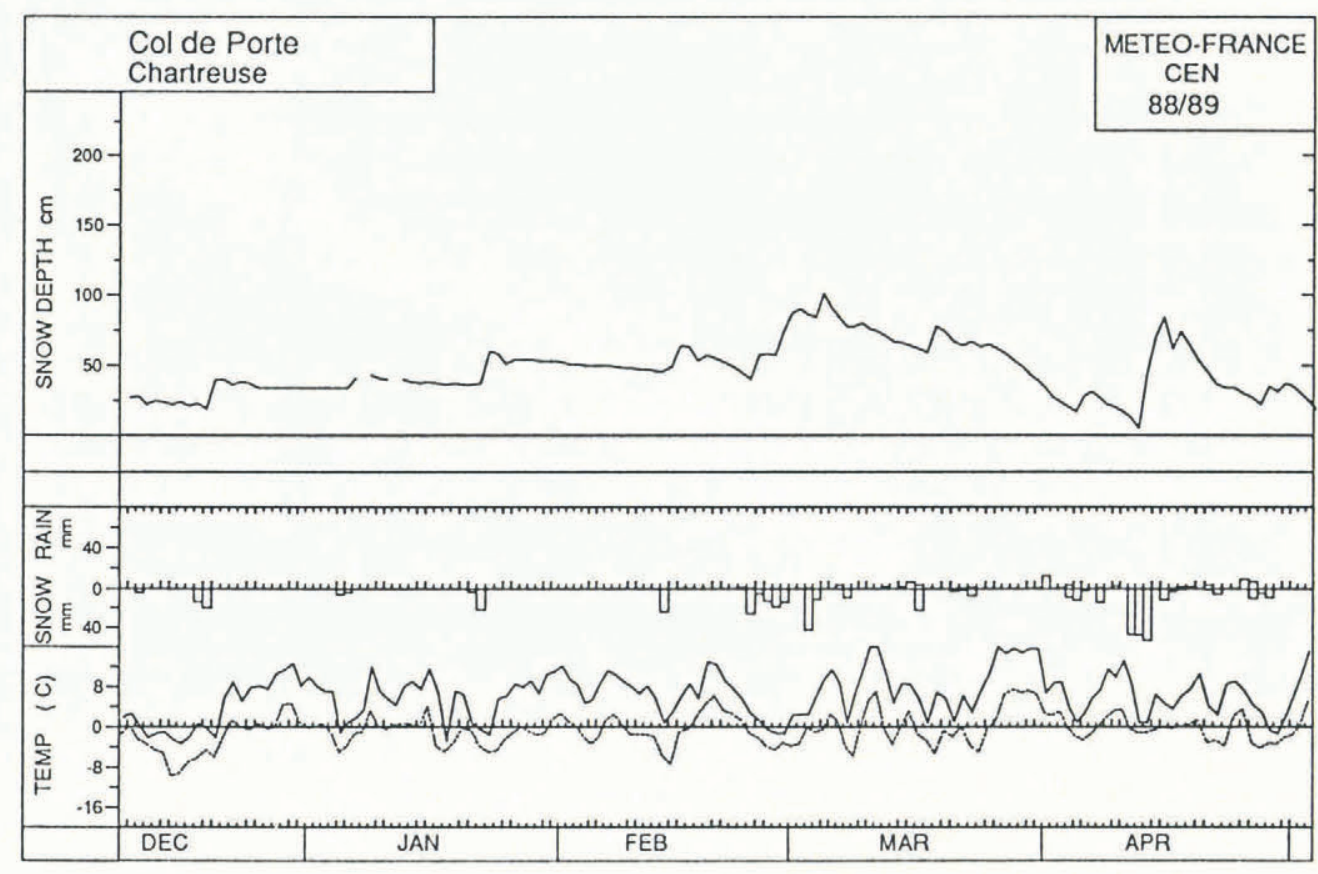

Fig. 3. Maximum and minimum daily temperature, snow and rain precpitation, and snow depth observed during the winter 1988-89 at Col de Porte. 


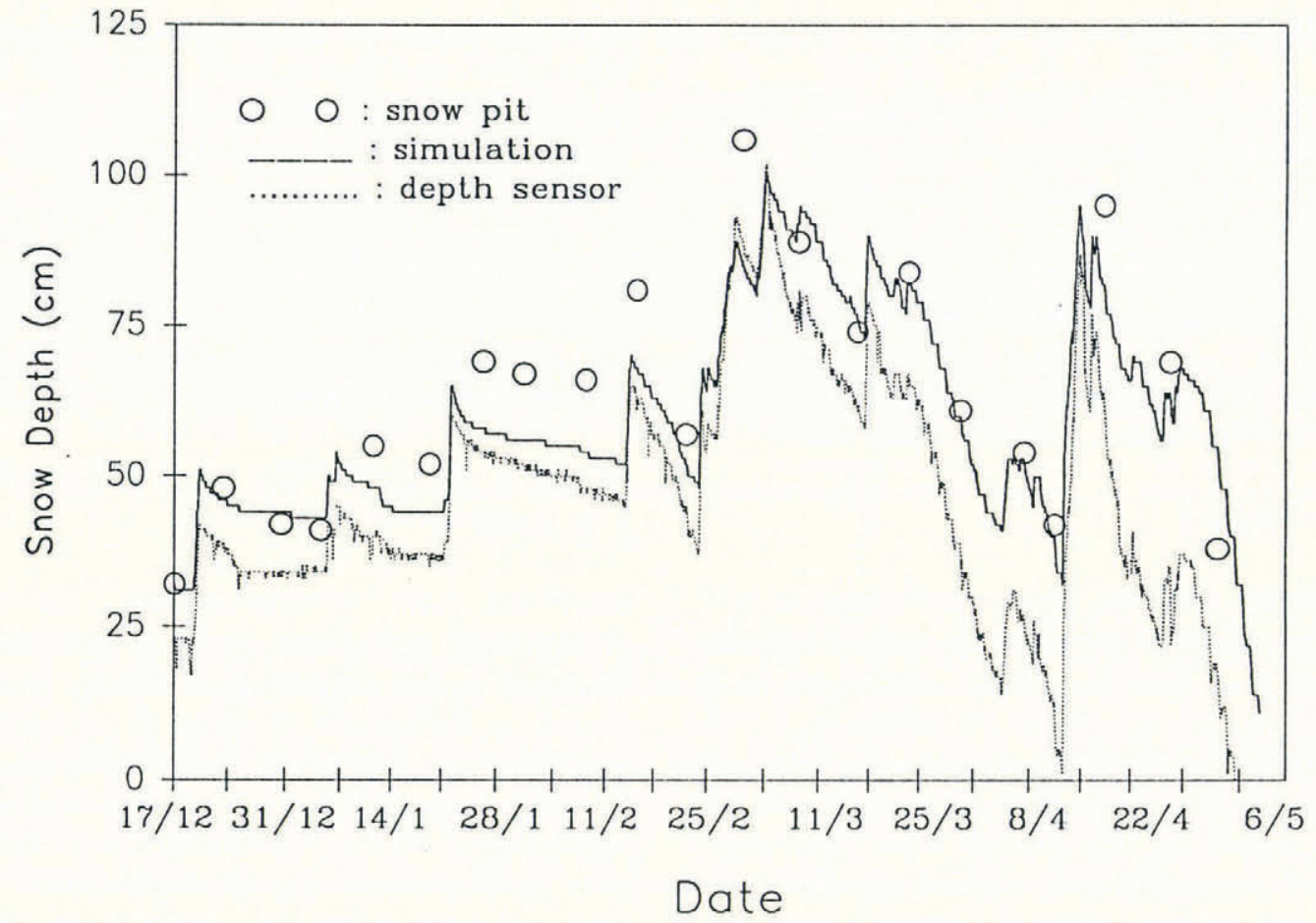

Fig. 4. Comparison between observed and simulated snow depth. ..., snow depth measured automatically with an ultrasonic sensor; o, snow depth deduced from the pit observations; -, simulated snow depth.

between snow depths increasing with time: at the initialization (17 December 1988), a difference was measured between the pit and snow depth measured with the ultrasonic sensor. During the simulation, this difference remained almost constant during the first 2 months and then it increased slightly with time until the end of the experiment. It derives probably from the difference in location between the short-wave radiometer and the ultrasonic sensor, which are more exposed to the Sun's radiation during spring, because of tall trees located southwards. This hypothesis is confirmed by the fact that the simulated snow depth is always very similar to the snow depth deduced from the pit observations we made once a week. Snow-depth comparison points out the improvement of the model due to the introduction of the metamorphism laws: in the middle of January, the model

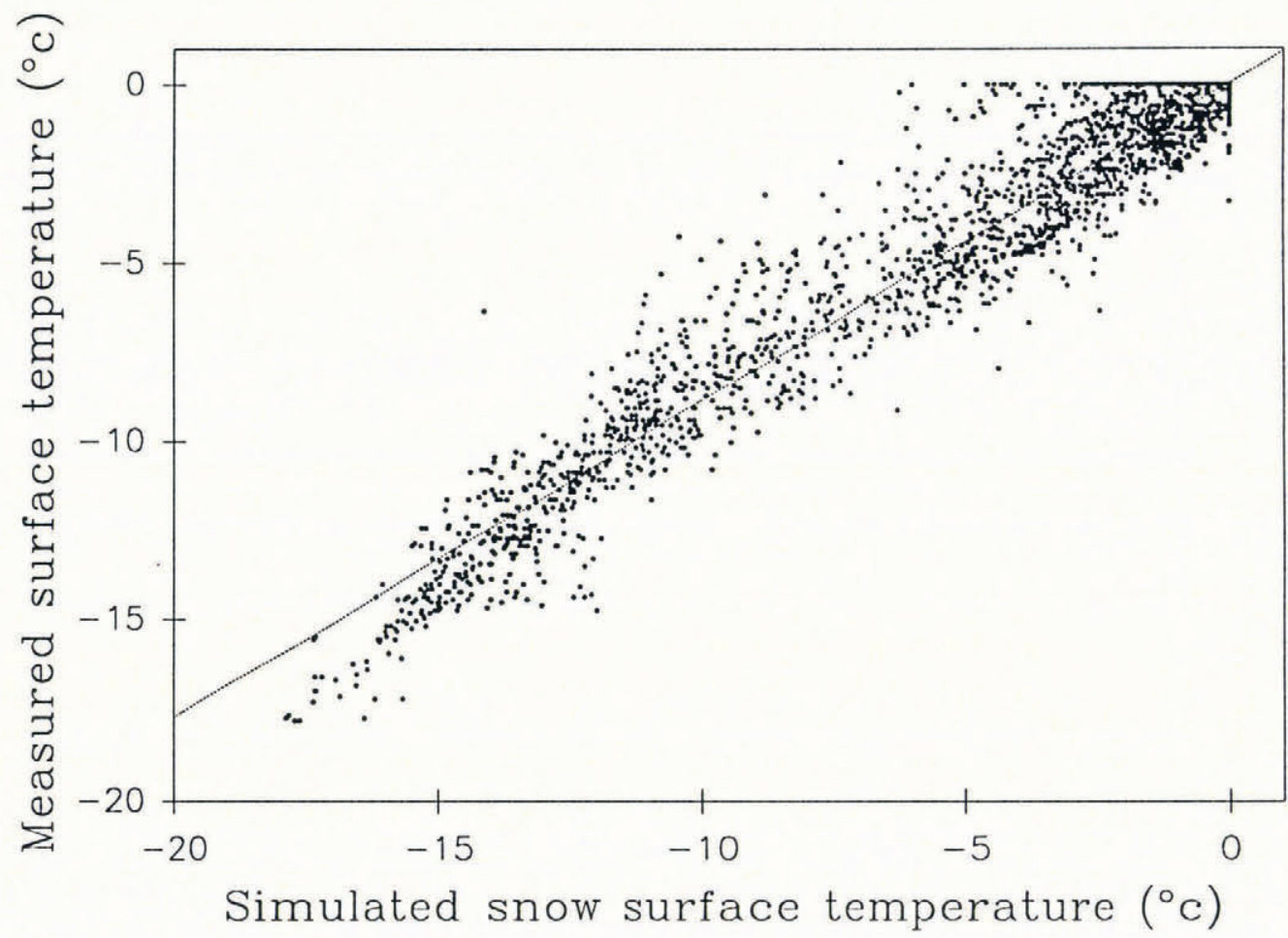

Fig. 5. Comparison between the simulated and the measured snow-surface temperature from 9 January to 6 May. 


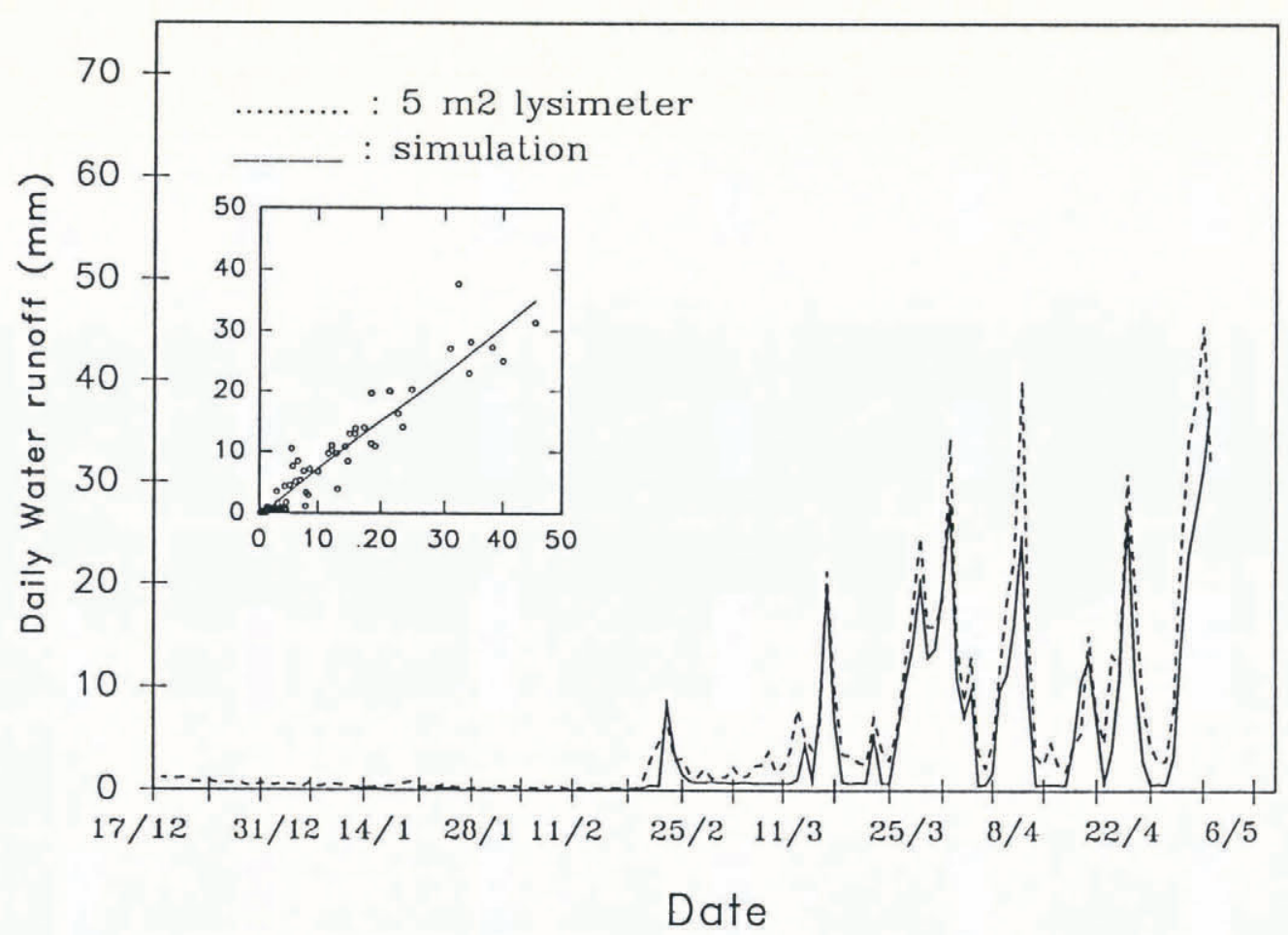

Fig. 6. Compared evolution of the simulated (-) and the measured (...) bottom-water run-off.

transformed the whole snowpack into depth hoar and so settlement was no more efficient, allowing the upper layers at a very low density, which induces a very low hardness and thus a potential instability if these layers were covered by heavy or windy snowfalls.

Energy balance was tested by comparing the measured and the simulated hourly snow-surface temperature in Figure 5. Snow-surface temperature was measured with an hemispheric pyradiometer. The correlation between the two series is equal to 0.97 over 2400 points from 9 January to 8 May. It proves how efficient the energy-balance calculation is and particularly the albedo prediction from snow grain-size, type and age.

Figure 6 compares measured and simulated daily bottom water run-off. Measurements were made using a $5 \mathrm{~m}^{2}$ lysimeter protected from lateral water flow by a $50 \mathrm{~cm}$ high crown. Once more, the model proved itself efficient in calculating the energy balance and water transmission, even during the melting period when the albedo is at a maximum. It must be noted that a traditional index method to calculate bottom-water runoff would have diagnosed a significant water run-off during January because of a very high temperature (up to $10^{\circ} \mathrm{C}$ ). The model allowed a cold snowpack, as observed in the field, calculating that radiative transfers and latentheat transfers balanced completely sensible-heat transfers, because of the very low air humidity (lower than $30 \%$ ).

Figure 7 compares the measured and the simulated snow profiles. Snow grains were characterized in the field by taking sub-samples out of each layer which were observed later under the microscope, as described in a previous section. Comparison between simulated and observed temperature and liquid-water-content profiles is not easy since they cannot be described by unidimensional parameters. The main features of snow cover (dry snowpack, internal wetting, refreezing) are correctly simulated throughout the whole winter. We note particularly that the model has perfectly simulated a cold snowpack up to the middle of February, despite very high prevailing air temperatures.

In the same way, the comparison between the main characteristics of the observed and simulated stratgraphical profiles shows very slight differences. To quantify the effects of these differences on snowpack stability, we used the expert system MEPRA (Giraud, in press). This model analyses the stability of snowpacks observed in the field or simulated by Crocus. MEPRA first classifies the stratigraphical profile within different classes. Then, it derives the shear-stress profile, assuming a slope of $45^{\circ}$, and compares it to the shear strength of each layer deduced from its snow type and its density (Coleou, 1990). Stability is then determined on a three-level danger scale. MEPRA was run on the 18 profiles observed at Col de Porte during the winter 1988-89 and on the corresponding profiles simulated by Crocus. Agreement on the danger level was obtained for 17 of these profiles, showing that, from the stability point of view, Crocus simulated a snowpack similar to the one observed.

As all types of grains were encountered during this season, it confirmed that the laws of metamorphism deduced from cold-laboratory experiments were suitable for introduction to the model. The simulation has shown well the formation of depth hoar until the middle of February, despite very high air temperatures. This is an example of the potential utility of such a model to describe snow cover in locations where pit observations are not available but where meteorological data could be measured or analysed.

Figure 8 shows the evolution of the simulated stratigraphy throughout the season. Colours correspond 

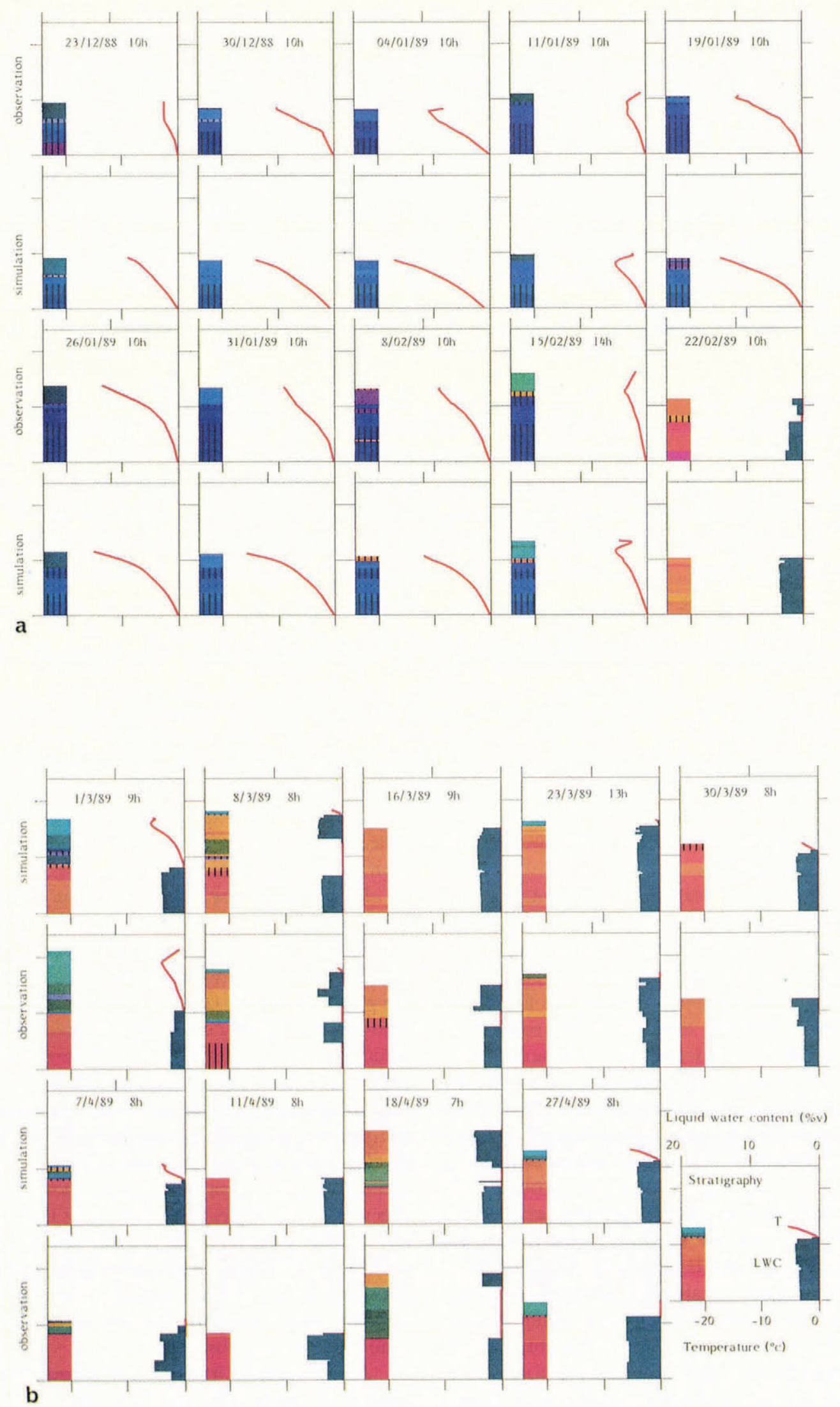

Fig. 7. Comparison between simulated and observed profiles and stratigraphy. Grain types are described by a colour coding. The correlation between these colours and the formalism used to describe snow is shown in Figure 8. Black vertical hachures show crusts. 


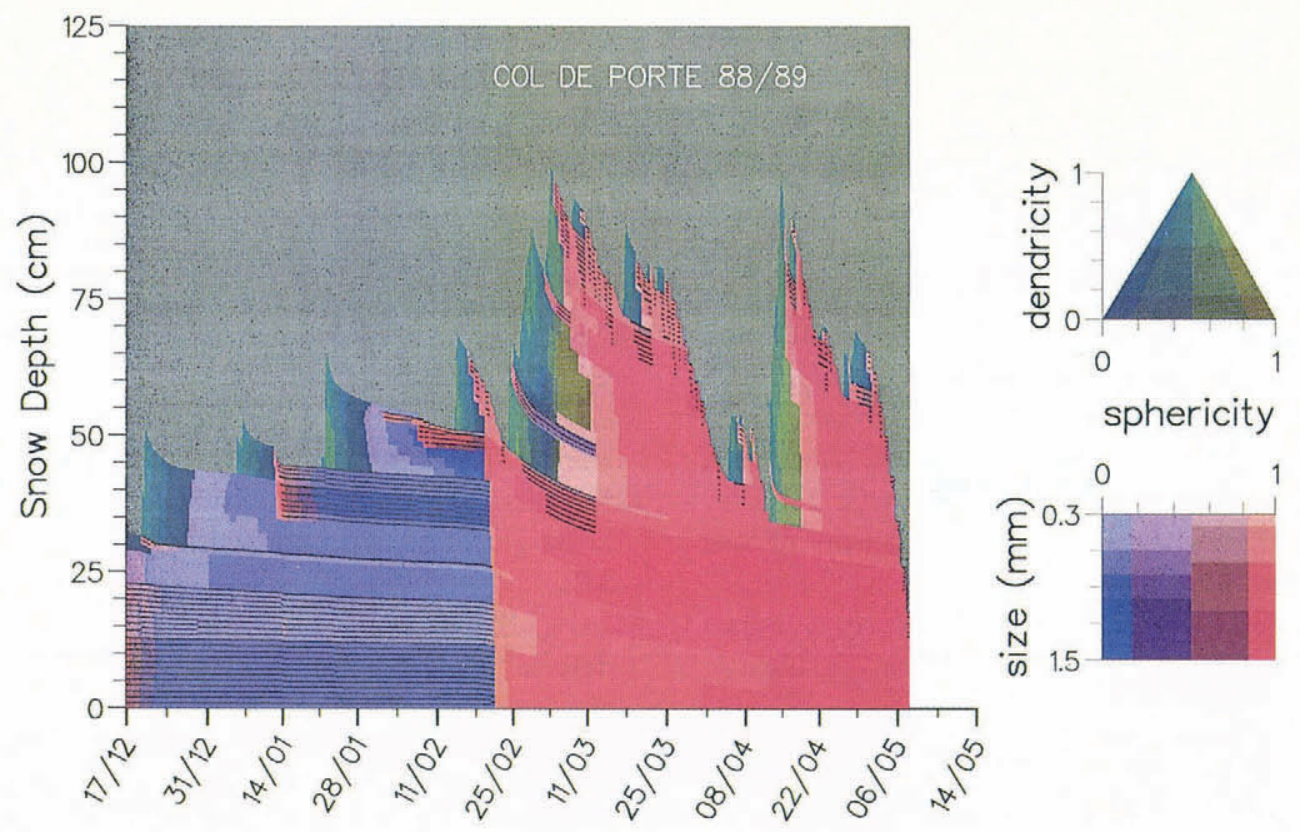

Date

Fig. 8. Continuous evolution of stratigraphy as simulated by the model throughout the whole winter season. Crusts are described by black horizontal hachures.

to the description of grains using the formalism introduced to quantify the metamorphism laws. In this figure, crusts are described by black horizontal hachures. These crusts are defined as layers that were previously wet (more than $0.5 \%$ per volume) and that are now frozen (temperature below $0.1^{\circ} \mathrm{C} \mathrm{m}^{-1}$ ). The formation of one of these crusts can be observed on 14 January at the snow-cover surface and on 1 March at a depth of $30 \mathrm{~cm}$ when the surface layer previously wetted on 23 February froze. The rapid transition from depth hoar and faceted crystals to rounded grains on 20 February is obvious. It was due to a complete wetting of the snowpack induced by a warm and half-overcast weather without rain. The wetting of the ground simulated by the model was confirmed in the field by the first important water run-off measured by the lysimeter (Fig. 6). It should also be noted how depth-hoar layers became settled after their metamorphism into wetgrain snow layers during this wetting period.

Despite good global agreement between the observations and the simulations, some defects in the model have not been resolved even today, especially concerning water transmission. Rain on fresh-snow events are characterized by a transmission of water in channels, which insulates the snow-cover surface (Kattleman, 1990). A unidimensional model like Crocus cannot simulate accurately these events which have two-dimensional characteristics. Theoretical work on this phenomenon (Morris and Kelly, 1990) has recently been conducted but it cannot easily be introduced into a complete simulation model.

Ice-lens formation is also poorly described by Crocus, which can only simulate crust formation without deriving how unpermeable they are.

Possible erosion of the snowpack by wind cannot easily be taken into account and, until now, windpumping effects (Colbeck, 1989a) have not been introduced into the model Crocus.

\section{CONCLUSION}

Introduction of metamorphism laws into the numerical model Crocus has improved significantly its efficiency. Stratigraphy simulation allows a much better description of snow albedo and also of snow-atmosphere heat exchanges. Furthermore, settlement of each layer of the snowpack has appeared to be more accurate using a settlement-law function of snow type.

Since the winter season 1989-90, the model Crocus has been used by the operational French avalancheforecasting services. The forecasters have a software of the model. To let it run, they have first to build up the meteorological parameters file necessary for the model, which needs time and thus limits the number of possible simulation locations, though the main interest of the model would be to simulate the snow cover at numerous locations under different orientations and altitudes. To improve this, we are now working on an automatic weather-analysis system which is able to determine everywhere in the French Alps the prevailing weather conditions at an hourly time-step. The system will use meteorological model outputs, the snow-weather avalanche network, numerous automatic weather stations, the radar network and also the meteorological satellite data. It will be allowed to run automatically the model Crocus in quasi-real time over different locations in the French Alps numerous enough to describe the snow cover in its whole diversity.

\section{REFERENCES}

Akitaya, E. 1974. Studies on depth hoar. Contrib. Inst. Low Temp. Sci., Ser. A 26.

Brun, E. 1989. Investigation on wet-snow metamorphism 
in respect of liquid-water content. Ann. Glaciol., 13, 2226.

Brun, E., E. Martin, V. Simon, C. Gendre and C. Coleou. 1989. An energy and mass model of snow cover suitable for operational avalanche forecasting. 7. Glaciol., 35(121), 333-342.

Christon, M., P. Burns, E. Thompson and R. Sommerfeld. 1987. Water vapor transport in snow. A 2-D simulation of temperature gradient metamorphism. In Jones, H. G. and W.J. Orville-Thomas, eds. Seasonal snowcovers: physics, chemistry, hydrology. Dordrecht, etc., D. Reidel Publishing Co., 37-62. (NATO ASI Series C, 211.)

Colbeck, S. C. 1973. Theory of metamorphism of wet snow. CRREL Res. Rep. 313.

Colbeck, S.C. 1980. Thermodynamics of snow metamorphism due to variations in curvature. 7. Glaciol., 26(94), 291-301.

Colbeck, S. C. 1983. Theory of metamorphism of dry snow. 7. Geophys. Res., 88(C9), 5475-5482.

Colbeck, S. C. 1989a. Air movement in snow due to windpumping. 7. Glaciol., 35(120), 209-213.

Colbeck, S. C. 1989b. Snow-crystal growth with varying surface temperatures and radiation penetration. $\mathcal{J}$. Glaciol., 35(119), 23-29.

Colbeck, S.C. and 7 others. 1990. The international classification for seasonal snow on the ground. Wallingford, Oxfordshire, International Association of Hydrological Sciences. International Commission on Snow and Ice.
Coleou, C. 1990. Mesure dans le manteau neigeux. Neige et Avalanches 52, 16-18.

Giddings, J. C. and E. LaChapelle. 1962. The formation rate of depth hoar. 7. Geophys. Res., 67(6), 2377-2383.

Giraud, G. In press. Modèle expert d'aide à la prévision du risque d'avalanches. Proceedings of Symposium ANENA CISA IKAR Chamonix, June 1991.

Gubler, H. and H.-P. Bader. 1989. A model of initial failure in slab-avalanche release. Ann. Glaciol., 13, 90-95.

Kattelmann, R. 1990. Liquid water at the snowpack surface. [Abstract.] Eos, 71(43), 1328.

Marbouty, D. 1980. An experimental study of temperature-gradient metamorphism. F. Glaciol., 26(94), 303312.

Morris, E. M. and R.J. Kelly. 1990. A theoretical determination of the characteristic equation of snow in the pendular regime. $\mathcal{F}$. Glaciol., 36(123), 179-187.

Pahaut, E. and D. Marbouty. 1981. Les cristaux de neige. II. Evolution. Neige et Avalanches 25, 3-42.

Sergent, C., P. Chevrand, J. Lafeuille and D. Marbouty. 1987. Caractérisation optique de différents types de neige. Extinction de la lumière dans la neige. $\mathcal{F}$. Phys. (Paris), 48, Colloq C1, 361-367. (Supplément au 3.)

Warren, S. G. 1982. Optical properties of snow. Rev. Geophys. Space Phys., 20(1), 67-89.

The accuracy of references in the text and in this list is the responsibility of the authors, to whom queries should be addressed. 